Ç.Ü. Sosyal Bilimler Enstitüsü Dergisi, Cilt 28, Sayı 2, 2019, Sayfa 198-213

\title{
“RESILIENCE” KAVRAMINA ÖRGÜT BAĞLAMINDA TÜRKÇE KARŞILIK ÖNERILLEİ
}

\author{
Merve GERCEK ${ }^{1}$ \\ Dilek YILMAZ BÖREKÇ $\dot{I}^{2}$
}

ÖZ

Bu çalıșmada, sosyoloji, psikoloji, işletme ve çeșitli mühendislik alanlarında kullanılan "resilience" kavramına, ișletme yönetimi ve endüstri mühendisliği alanlarındaki çalıșmalarda kullanılmak üzere örgüt bağlamında Türkçe bir karşılık önerilmesi amaçlanmıştır. Esneklik, geri sıçrama, eski haline dönme ve uyum sağlayabilme gibi anlamları bulunan "resilience" kavramının farklı yaklaşımlar çerçevesinde aynı anlamda kullanılmadığı görülmüştür. Söz konusu kavramın farklı anlamlarda kullanılması, Türkçe çalışmalarda birbirinden farklı kelimelerin tercih edilmesine yol açmaktadır. Bu çalışmada, örgüt ve çalışan bağlamında kullanılan "resilience" kavramını diğer akademik disiplinlerdeki kullanımından ayrıştırarak yeni bir kelime üzerinde görüş birliğine varılması için önerilerde bulunulmuştur. Bu öneriler, Türkiye'deki dilbilimciler ve ilgili alanlardaki uzmanların değerlendirilmesine sunulmustur. Örgüt ve calıșan bağlamında "resilience" kavramı için tercih edilecek ayrıştıııı bir karşılığın öğrenciler, araştırmacılar ve uygulamacılar için Türkçe çalışmaların anlașılabilirliğinin ve ulașılabilirliğinin artıııılmasında faydalı olması beklenmektedir.

Anahtar Kelimeler: Resilience, Örgütsel Dayanıklılık, Dayanıklılık

\section{PROPOSAL OF TURKISH EQUIVALENTS FOR "RESILICENCE" CONCEPT IN ORGANIZATIONAL CONTEXT}

\begin{abstract}
The purpose of this study is to provide a Turkish equivalent for the concept of "resilience", oftenly used in sociology, psychology, business administration and various engineering fields, in the context of organizational studies. Resilience, which has the meaning of flexibility, bouncing back and adaptability, have been observed to be in use with different connotations within the frameworks of different approaches. The use of the concept with different meanings leads to the preference of different words in Turkish studies. In this study, the concept of "resilience" is treated in the context of organization and employee. It is aimed to differentiate the concept from its uses in other academic disciplines and suggestions are provided for reaching a consensus on a new word or a group of words. These recommendations are presented to the evaluation of linguists and experts in related fields in Turkey. In the context of the organization and the employee, a distinctive new equivalent to the concept of "resilience" is expected to be useful for students, researchers and practitioners in improving the intelligibility and the accessibility of Turkish studies.
\end{abstract}

Keywords: Resilience, Organizational Resilience, Psychological Resilience

\footnotetext{
${ }^{1}$ Dr. Öğr. Üyesi, Kocaeli Üniversitesi, Hereke MYO, merve.gercek@kocaeli.edu.tr, ORCID: 0000-00027076-8192

${ }^{2}$ Doç.Dr., İstanbul Üniversitesi-Cerrahpaşa, Mühendislik Fakültesi, dborekci@istanbul.edu.tr, ORCID: 00000002-0055-4869

Received/Geliş: 07/07/2019 Accepted/Kabul: 09/09/2019, Derleme/ Conceptual article

Cite as/Alıntı: Gerçek, M., Yılmaz Börekçi, D. (2019), "Resilience Kavramına Örgüt Bağlamında Türkçe

Karşılık Önerileri”, Çukurova Üniversitesi Sosyal Bilimler Enstitüsü Dergisi, cilt 28, sayı 2, s.198-213.
} 


\section{Giriş}

Günümüzde uluslararası bilim alanında giderek artan oranda çalışılan "resilience" olgusunun Türkçe çalışmalarda kullanımı konusunda bir dil ve anlam birliği sorunu olduğu gözlenmektedir (Yılmaz Börekçi ve Gerçek, 2017). Hemfikir olunan ve söz konusu kavramın güncel anlamını ifade eden bir karşılığın üretilmesi durumunda, Türkiye kökenli çalışmaların disiplinler arası bütünleştirilmesi ve geliştirilmesi ivmelenecektir. Aynı zamanda, Türkçe yayınlanacak çalışmalarda ortak görüş birliğine varılan bir Türkçe karşılığın kullanılması öğrenciler, araştırmacılar ve uygulamacılar açısından çalışmaların anlaşılabilirliğine ve ulaşılabilirliğine katkı sağlayacaktır. Bu çalışma ile bu arayışa katkı sunmak amaçlanmaktadır.

"Resilience" kavramı, genellikle dayanıklılı, esneklik, uyum sağlayabilme, toparlanabilme ve eski haline dönebilme gibi anlamları karşılamak için çeşitli akademik disiplinlerde kullanılmaktadır. Fizik ve mekanik disiplinlerinde "resilience" kavramının maddelerin esnekliği ve zorlandıktan sonra eski haline dönme gücü olarak tanımlandığ 1 görülmüştür (Klein, Nicholls ve Thomalla, 2003). Önceleri maddelerin fiziksel bir özelliği olarak tanımlanan” resilience” kavramı Timmerman’ın (1981) çalışmalarından sonra sosyal bilimler alanında da sıklıkla karşılaşılan bir kavram haline gelmiştir. "Resilience" kavramı, sosyal bilimler alanında iktisat, işletme, sosyoloji gibi disiplinlerde sistemlerin krizler ya da beklenmedik olumsuzluklar karşısında ayakta durabilme, eski haline gelebilme ve değişimlere uyum sağlayarak yeni yetenekler kazanması anlamında kullanılmaktadır. Psikoloji, eğitim ve tıp gibi disiplinlerde ise "resilience" kavramının, bireylerin hayatlarını herhangi bir şekilde etkileyebilecek olumsuzluklara karşı başa çıkabilme, kendini toparlayabilme ve uyum sağlayabilme şeklinde tanımlanan bireysel bir özellik olarak ele alınmaktadır.

Uluslararası çalışmalarda, "resilience" kavramının ele alınış biçiminin, bu kelimenin önüne belirleyici bir kelime daha eklenerek (örn. psychological resilience, organizational resilience, career resilience) ayrıştırma yapıldığı ancak, Türkiye kökenli çalışmalarda birbirinden farklı kelimelerin tercih edildiği görülmüştür (Yılmaz Börekçi ve Gerçek, 2017). Bu çalışmada, işletme alanı başta gelmek üzere, endüstri mühendisliği, iktisat, örgüt sosyolojisi gibi işletme bağlamında yapılan çalışmalarda "resilience" kavramı için diğer disiplinlerde kullanılan tanımlardan ayrıştırıcı bir Türkçe karşılık önerisi sunmak amaçlanmıştır. Bu amaç çerçevesinde, çalışmanın ilk kısmında "resilience" kavramının tanımlarına ve farklı disiplinlerde nasıl kullanıldığına değinilmiştir. Ardından, bu çalışmanın hedef aldığı akademik bağlam olan örgüt ve çalışan bağlamları açısından "resilience" kavramının nasıl tanımlandığı ve özellikleri irdelenmiştir. Bir sonraki bölümde, Türkiye kökenli çalışmalarda sosyal bilimler alanında tercih edilen Türkçe karşılıklar açıklanmış ve "resilience" kavramının örgüt ve çalışan bağlamında ayırt edicilikleri değerlendirilmiştir. Son olarak, Türkçe karşılık önerilerinde bulunulmuş ve sunulan bilgiler değerlendirilmiştir.

\section{"Resilience" Kavramının Tanımları ve Kullanımları}

İngilizce "Resilience" olarak yazılan ve bazı Türkçe kaynaklarda İngilizce okunuşu "rezilyans" olarak kullanılan esneklik, dayanıklılık, geri sıçrama gibi anlamlarda kullanılan "resilience" kelimesinin kökeni, Latince bir kelime olan "resilire"den gelmektedir. "Resilire", Latince'de sıçrama veya geri gelme, sekme, geri çekilme ve 
Ç.Ü. Sosyal Bilimler Enstitüsü Dergisi, Cilt 28, Sayı 2, 2019, Sayfa 198-213

eski haline geri dönme anlamlarını taşımaktadır (Latin-Dictionary). Günümüzde "resilience" kelimesinin, İngilizce'deki anlamlarından bazıları aşağıdaki gibidir:

- Zorluklardan çabuk düzelme kapasitesi; dayanıklılık (Oxford English Dictionary),

- Bir maddenin veya nesnenin yeniden şekillenebilmesi; esneklik (Oxford English Dictionary)

- Gerilmiş bir gövdenin özellikle basınç gerilmesinin neden olduğu deformasyondan sonra boyutunu ve şeklini geri kazanabilmesi (MerriamWebster Dictionary),

- Bir talihsizlik veya değişim sonrası kolayca iyileşebilme ya da uyum sağlayabilme becerisi (Merriam-Webster Dictionary),

- Zor ya da kötü bir şey olduktan sonra tekrar mutlu, başarılı, vb. olma yeteneği (Cambridge English Dictionary),

- Bir maddenin büküldükten, esnetildikten veya preslendikten sonra olağan şekline dönme yeteneği (Cambridge English Dictionary),

- Sorunların ardından bir önceki iyi duruma hızla geri dönebilme kalitesi (Cambridge English Dictionary)

"Resilience" kelimesinin İngilizce tanımlarına bakıldığında, fiziksel bir maddenin esneklik ve yeniden eski haline gelebilme özelliği açısından somut bir özellik olarak ve sorunların ardından iyileşebilme ve dayanıklılık özelliği açısından soyut bir özellik ve süreç olarak iki farklı şekilde tanımlanmış olduğunu söylemek mümkündür. Bu ayrım doğrultusunda, "resilience” kavramının 1970'ler öncesinde daha çok mekanik biliminde maddelerin fiziksel dayanıklılığı ve esnekliğini ifade etmek için kullanıldığ görülmektedir (Klein vd., 2003). "Resilience" kavramının sosyal bilimlerde kullanılan bir kavram haline gelmesi, Holling'in (1973) ekosistemler üzerinde yürüttüğü çalışmalarla başlamıştır. Holling (1973), ekosistemlerin devamlılığını incelerken, sistemlerin geçici bir rahatsılıktan sonra dönme yeteneğini ifade etmede "resilience" kavramını kullanmıştır. Yazar bu kavramı kullanırken, sabit sistemlerden farklı olarak "resillient-resilience özelliğine sahip olan” sistemlerin değişimlerin üstesinden gelebilecek dinamikliğe sahip olduğunu öne sürmüştür.

Sosyal bilimlerde "resilience" kavramını en belirgin şekilde kullanan ilk araştırmac1, toplumların "resilience" düzeylerini inceleyen Timmerman (1981) olmuştur. Yazar, toplumlar, toplumdaki kurumlar ve ekonomilerin davranışsal etkileşimlerini açıklayabilmek için "resilience" kavramını kullanmıştır. Yazara göre "resilience", bir sistemin ya da sistemin parçasının, tehlikeli bir olayın oluşmasının ardından sağ kalma yeteneğinin bir ölçütüdür.

"Resilience" kavramının fiziksel sistemler, ekonomik sistemler, sosyoekonomik sistemler, psikoloji, afet yönetimi, işletme ve mühendislik alanlarında farklı kullanım şekillerinin olduğu görülmüştür. "Resilience" kavramını anlayabilmek için farklı yaklaşımları ve kullanım alanlarını gözden geçirmekte fayda bulunmaktadır. (Ponomarov ve Holcomb, 2009). Tablo 1'de "resilience" kavramının farklı yaklaşımlara göre tanımları sunulmuştur. 
Ç.Ü. Sosyal Bilimler Enstitüsü Dergisi, Cilt 28, Sayı 2, 2019, Sayfa 198-213

Tablo 1. Rezilyans Kavramının Tanımları

\begin{tabular}{|c|c|c|}
\hline Yazar & Yaklaşım & Tanım \\
\hline Bodin ve Wiman (2004) & $\begin{array}{l}\text { Fiziksel } \\
\text { sistemler }\end{array}$ & $\begin{array}{l}\text { Bir yer değiştirmenin ardından sistemin denge } \\
\text { noktasına ulaşma hızı }\end{array}$ \\
\hline Holling (1973) & $\begin{array}{l}\text { Ekolojik } \\
\text { sistemler }\end{array}$ & $\begin{array}{l}\text { Sistemlerin sürekliliği, değişime ve düzenin } \\
\text { bozulmasına dayanarak durum değişkenleri } \\
\text { arasındaki ilişkileri devam ettirebilme } \\
\text { kabiliyetinin ölçütü }\end{array}$ \\
\hline $\begin{array}{l}\text { Walker, Holling, } \\
\text { Carpenter ve Kinzig } \\
\text { (2004) }\end{array}$ & $\begin{array}{l}\text { Ekolojik } \\
\text { sistemler }\end{array}$ & $\begin{array}{l}\text { Bir sistemin herhangi bir bozulmaya dayanması } \\
\text { ve devam eden değişim karşısında yeniden } \\
\text { organize olurken mevcut işlevi, yapısı, } \\
\text { kimliğini ve geri veri akışını geri kazanma } \\
\text { kapasitesi }\end{array}$ \\
\hline Gunderson (2000) & $\begin{array}{l}\text { Ekolojik } \\
\text { sistemler }\end{array}$ & $\begin{array}{l}\text { Bir sistemin, davranışı kontrol eden değişken } \\
\text { etmenler ve süreçlerin yapıyı bozmasından } \\
\text { önce katlanabileceği bozulmanın büyüklüğü }\end{array}$ \\
\hline $\begin{array}{l}\text { Tilman ve Downing } \\
\text { (1994) }\end{array}$ & $\begin{array}{l}\text { Ekolojik } \\
\text { sistemler }\end{array}$ & $\begin{array}{l}\text { Bir sistemin, bozulmanın ardından denge } \\
\text { noktasına dönme hızı }\end{array}$ \\
\hline Timmerman (1981) & $\begin{array}{l}\text { Sosyo- } \\
\text { ekonomik } \\
\text { sistemler }\end{array}$ & $\begin{array}{l}\text { Bir sistemin ya da sistemin parçasının, tehlikeli } \\
\text { bir olayın oluşmasından sağ kalma yeteneğinin } \\
\text { ölçütü }\end{array}$ \\
\hline $\begin{array}{l}\text { Walker, Carpenter, } \\
\text { Anderies, Abe, } \\
\text { Cumming, Janssen, } \\
\text { Pritchard (2002) }\end{array}$ & $\begin{array}{l}\text { Sosyo- } \\
\text { ekonomik } \\
\text { sistemler }\end{array}$ & $\begin{array}{l}\text { Bir sistemin, herhangi bir bozulma sistemin } \\
\text { yapısını ve işlevini değiştirdiyse yeniden } \\
\text { organize olabilmek ya da yenilenebilmek için } \\
\text { gerekli öğeleri elde edebilme ve işlevselliğini } \\
\text { sürdürebilme kabiliyeti }\end{array}$ \\
\hline $\begin{array}{l}\text { Carpenter, Walker, } \\
\text { Anderies ve Abel (2001) }\end{array}$ & $\begin{array}{l}\text { Sosyo- } \\
\text { ekonomik } \\
\text { sistemler }\end{array}$ & $\begin{array}{l}\text { Bir sistemin, başka bir takım süreçler } \\
\text { tarafindan kontrol edilerek farklı bir duruma } \\
\text { geçmesinden önce katlanabildiği bozulmanın } \\
\text { büyüklüğü }\end{array}$ \\
\hline $\begin{array}{l}\text { Luthans, Vogelgesang ve } \\
\text { Lester (2006) }\end{array}$ & Psikoloji & $\begin{array}{l}\text { Karşı1tlık durumundan geliştirilebilir geri } \\
\text { sıçrayabilme kapasitesi }\end{array}$ \\
\hline Coutu (2002) & Psikoloji & $\begin{array}{l}\text { Gerçekliğin kabulü, hayatın anlamlılığına dair } \\
\text { güçlü bir inanç ve doğaçlama kabiliyetine sahip } \\
\text { bireyler }\end{array}$ \\
\hline $\begin{array}{l}\text { Bruneau, Chang, Eguchi, } \\
\text { Lee, O’Rourke, } \\
\text { Reinhorn, Shinozuka, } \\
\text { Tierney, Wallace ve von } \\
\text { Winterfeldt, (2003) }\end{array}$ & Afet yönetimi & $\begin{array}{l}\text { Sosyal birimleri tehlikeleri yatıştırma, gelecek } \\
\text { depremlerin etkilerini azaltacak ve sosyal } \\
\text { bozulmaları minimize edecek iyileştirme } \\
\text { faaliyetleri gerçekleştirme kabiliyeti }\end{array}$ \\
\hline $\begin{array}{l}\text { Paton, Smith ve Violanti } \\
\text { (2000) }\end{array}$ & Afet yönetimi & $\begin{array}{l}\text { Kendini düzeltme, öğrenilmiş beceriklilik ve } \\
\text { büyüme süreci, bireyin önceki denetimleri ve } \\
\text { yeteneklerinden daha yüksek düzeyde } \\
\text { psikolojik olarak işlev göstermesi }\end{array}$ \\
\hline $\begin{array}{l}\text { Hollnagel, Woods ve } \\
\text { Leveson (2006) }\end{array}$ & Mühendislik & $\begin{array}{l}\text { Farklılaşma, değişim, zarar görme, bozulma ve } \\
\text { sürprizleri sezme, tanıma, uyum sağlama ve } \\
\text { ortadan kaldırma yeteneği }\end{array}$ \\
\hline $\begin{array}{l}\text { Hamel ve Valikangas } \\
\text { (2003) }\end{array}$ & $\begin{array}{l}\text { İşletme/Örgüt } \\
\text { Bağlamı }\end{array}$ & Sürekli yeniden inşa kapasitesi \\
\hline Horne ve Orr (1998) & İşletme/Örgüt & Bir olayın beklendik döngüsünü bozan belirgin \\
\hline
\end{tabular}


Ç.Ü. Sosyal Bilimler Enstitüsü Dergisi, Cilt 28, Sayı 2, 2019, Sayfa 198-213

\begin{tabular}{l|l|l}
\hline & Bağlamı & $\begin{array}{l}\text { değişimlere üretken şekilde cevap verme } \\
\text { özelliği }\end{array}$ \\
\hline McDonald (2006) & $\begin{array}{l}\text { İşletme/Örgüt } \\
\text { Bağlamı }\end{array}$ & $\begin{array}{l}\text { Çevreyi yönetebilme ve çevrenin ihtiyaçlarına } \\
\text { uyum sağlayabilme özellikleri }\end{array}$ \\
\hline
\end{tabular}

Bhamra, R., Dani, S., ve Burnard, K. (2011)'den uyarlanmıştır.

"Resilience" kavramı sosyo-ekonomik sistemler açısından bir sosyal sistemin, daha önce gerçekleşmiş felaketlerden öğrenmesi ve gelecekte hazırlıklı olabilmek için kendisini düzenleyebilme kapasitesini ifade etmektedir. Sosyo-ekonomik sistem kapasitesi, bir örgüt ya da toplumun, beklenmedik bir talihsizliğin sonuçlarını ya da felaketlerin gerçekleşme riskini azaltmak için kullanabileceği tüm güçlü yanları, kaynakları ve yetenekleridir (Ponomarov ve Holcomb, 2009).

Psikoloji yazınında temelleri klinik çalışmalara dayanan "resilience" kavramı, ilk çalışmalarda sadece bazı insanların sahip olduğu olağanüstü bir özellik olarak görülürken, günümüzde bireylerin sahip olması gereken hayati bir yetkinlik olarak düşünülmektedir. Pozitif örgütsel davranış anlayışııın öncülerinden Luthans'a göre (2002), "resilience" kavramı pozitif psikolojik sermayenin bir alt unsurudur. Luthans, Vogelgesang ve Lester'a göre (2006) "resilience", karşıtlık durumundan geri sıçrayabilme kapasitesidir. "Resilience", bireysel düzeyde kişiye olumsuz durumların ardından eski durumuna dönme ve daha etkili bir sorunlarla başa çıkma kapasitesini oluşturmasında, gelişmesinde ve ilerleyişinde katkıda bulunan bir özellik olarak ele alınmaktadır. Bunların yanı sıra, "resilience" kavramı işyerinde bireysel performans ile ilişkili bir kavram olarak incelenerek ölçülebilir bir nitelik kazanmıştır (Block ve Kremen, 1996; Wagnild ve Young, 1993; Coutu, 2002; Waite ve Richardson, 2004; Luthans vd., 2006).

"Resilience" kavramının örgüt bağlamında kullanımı, ekonomik krizlerin yaygınlaşması, bilişim teknolojilerindeki hızlı gelişimle birlikte ortaya çıkan yeni ihtiyaçlar ve değişen çevre koşulları ile birlikte artan belirsizlik ve çetin rekabet ortamının yarattığı sorunlarla daha belirgin bir artış göstermiştir. Bunun başlıca sebeplerinden birisi de "resilience" kavramının felaket, talihsizlik, olumsuz ve beklenmedik olaylarla ilgili olması bakımından örgütsel süreçlerle bağlantı kurabilecek bir kavram olmasıdır. Horne ve Orr'a göre (1998), "resilience" bir olayın beklendik döngüsünü bozan belirgin değişimlere üretken şekilde cevap verme özelliğidir. McDonald (2006) ise "resilience" 1 , bir örgütün çevreyi yönetebilme ve çevrenin ihtiyaçlarına uyum sağlayabilme özellikleri olarak tanımlamıştır.

\section{Örgütsel (Organizasyonel) Bağlamda "Resilience" Kavramı (Organizational Resilience)}

Örgütsel bağlamda "resilience" kavramı, bir örgütün iyileşebilme (Sutcliffe ve Vogus, 2003), uyum sağlayabilme (Holling, 2001; Sutcliffe ve Vogus, 2003; Chang-Richards, Wilkinson, Seville, ve Brunsdon, 2013; Lee, Vargo ve Seville, 2013; Nilakant, Walker, van Heugten, Baird ve de Vries, 2013), ve dönüşebilme (Hamel ve Valikangas, 2003; Lengnick-Hall ve Beck, 2009; Seville, Stevenson, Brown, Giovinazzi, ve Vargo, 2014; Seville, 2018) yeteneklerini ifade etmektedir. İyileşme yetenekleri örgütlerin hayatta kalmalarına yardımcı olurken, uyum sağlama ve dönüşebilme yetenekleri ise 
Ç.Ü. Sosyal Bilimler Enstitüsü Dergisi, Cilt 28, Sayı 2, 2019, Sayfa 198-213

sürdürülebilirliğe katkı sağlamaktadır. Bir başka deyişle örgütlerin, felaketler karşısında aldıkları yaralardan iyileşerek toparlanabilmeleri, hayatını devam ettirmesiyle ilgili bir durumdur. Ancak, örgütlerin bir krizi atlattıktan sonra hayatta kalmaları, gelecekte karşılaşabilecekleri farklı krizler sonucunda devamlılığının garantisi olmamaktadır. Bu bağlamda, örgütlerin uyum sağlayabilme ve gerektiğinde dönüşüm geçirebilme özelliklerinin sürdürülebilirlik için oldukça gerekli olduğu düşünülmektedir.

Örgütsel bağlamda "resilience" kavramı çeşitli yazalar tarafından değişik biçimlerde tanımlanmıştır. Yapılan tanımlara bakıldığında, beklenmedik ve zorlayıcı durumların ardından hayatta kalmak ve bu durumlara uyum sağlayarak dönüşme yeteneği olmak üzere iki farklı yaklaşımın bulunduğu görülmektedir çeşitli tanımları bulunmaktadır (Tablo 2).

Tablo Hata! Belgede belirtilen stilde metne rastlanmadı.. Örgütsel Bağlamda "Resilience" Tanımları

\begin{tabular}{|c|c|}
\hline Yazar & Tanım \\
\hline Wildavsky (1988) & Zamanla büyüyen ve gelişen dinamik bir örgütsel uyum kabiliyeti \\
\hline Horne ve Orr (1998) & $\begin{array}{l}\text { Öngörülemeyen ve beklenen düzeni bozan belirgin bir değişime } \\
\text { üretken şekilde cevap verebilmenin temel bir özelliği }\end{array}$ \\
\hline Mallak (1998) & $\begin{array}{l}\text { Asgari düzeyde stresle başa çıkarken acil durumlara olumlu uyumcul } \\
\text { davranışlar tasarlama ve gösterebilme kabiliyeti }\end{array}$ \\
\hline Coutu (2002) & $\begin{array}{l}\text { Organizasyonun gerçeklikle yüzleşmesi, açıkça görülmeyen } \\
\text { çözümleri ortaya çıarabilme ve güçlüklerden anlam çıkarabilme } \\
\text { kabiliyeti }\end{array}$ \\
\hline $\begin{array}{l}\text { Sutcliffe \& Vogus } \\
\text { (2003), Vogus \& } \\
\text { Sutcliffe (2007) }\end{array}$ & $\begin{array}{l}\text { Organizasyonun zorlayıcı koşullara karşı gösterdiği uyumun } \\
\text { devamlılığı ve bu koşulların üstesinden daha güçlü bir halde } \\
\text { gelebilmesi }\end{array}$ \\
\hline $\begin{array}{l}\text { Hamel ve Valikangas } \\
(2003)\end{array}$ & Devaml yeniden yapılanma kapasitesi \\
\hline Fiksel (2007) & $\begin{array}{l}\text { Değişimlere karşı hayatta kalma, uyum gösterme ve büyüme } \\
\text { kapasitesi }\end{array}$ \\
\hline McDonald (2006) & $\begin{array}{l}\text { Çevrenin ihtiyaçlarına uyum sağlayabilme ve çevrenin değişkenliğini } \\
\text { yönetebilme kabiliyeti }\end{array}$ \\
\hline $\begin{array}{l}\text { Hollnagel, Woods ve } \\
\text { Leveson (2006) }\end{array}$ & $\begin{array}{l}\text { Değişkenlik, değişim, bozulma, parçalama ve sürprizleri tespit etme, } \\
\text { tanıma ve uyum sağlama kabiliyeti }\end{array}$ \\
\hline $\begin{array}{l}\text { Lengnick-Hall, Beck } \\
\text { ve Lengnick-Hall } \\
\text { (2011) }\end{array}$ & $\begin{array}{l}\text { Organizasyonun yaşamını tehdit eden yıkıcı olaylara etkin bir şekilde } \\
\text { dayanabilme, duruma özgü cevaplar geliştirebilme ve dönüşümcü } \\
\text { faaliyetleri gösterebilme kabiliyeti }\end{array}$ \\
\hline
\end{tabular}

Ponis ve Koronis (2012)'den uyarlanmıştır.

Akgün ve Keskin (2014)'e göre, bir organizasyonun yıkım sonrası eski haline dönme kapasitesi ve anılan "resilience" kavramı, bu bakış açısıyla pasif bir değişken olarak görülmektedir. Yazarlara göre, bir örgütün yalnızca ürün kaynaklı sorunlara cevap aramasındansa, proaktif adımlar atması ve değişken çevre koşullarında veya beklenmedik olaylar daha gerçekleşmeden, yeni ve daha iyi ürünler üretebilmesi, yeni yetenekler ve beceriler geliştirilebilmesi, "resilience" kavramının ürün yenilikçiliği (product innovation) bağlamında kullanılacak aktif bir özelliktir. Lengnick-Hall ve 
Beck'in (2009) ifadesiyle bir örgütün "resilience" kapasitesi (resilience capacity), bir örgütün kararlı bir şekilde ilerlemesini ve yıkıcı olayların zayıflatıcı sonuçlarının üstesinden gelmesini sağlayacak bireysel düzeydeki bilgi, beceri ve yetenek ile örgütsel rutinlerden oluşan bütünleşik bir seti ifade etmektedir. Ayrıca, örgütsel "resilience" kapasitesini oluşturan bilgi, beceri, yetenek ve diğer özelliklerin geliştirilmesinde bireysel düzeyde "resilience" kapasitesinin geliştirilmesi ve bazı stratejik insan kaynakları yönetiminin de rolü önem taşımaktadır (Lengnick-Hall vd., 2011).

Sutcliffe ve Vogus (2003) "resilience" kavramını bireylerin, grupların ve örgütlerin güçlüklerin üzerinden gelme, zorluklara rağmen faaliyetlerini sürdürebilme ve daha güçlü hale gelme olarak tanımlamışlardır. Carmeli, Friedman ve Tishler (2013)'a göre "resilience" kavramı, zorlukla mücadele ve bu duruma uyum becerisi olarak iki boyutlu bir yapıya sahiptir. "Resilience" kavramı, beklenmeyen olaylarla başa çıkma ve örgütsel öğrenmeye olanak tanıyan bilişsel, duygusal, ilişkisel ya da işlevsel kaynakların yaratılması ya da korunması sonucu ortaya çıkmaktadır. "Resilience", örgütsel yetkinliği geliştiren, verimliliği arttıran ve yeni yeteneklerle örgütlerin büyümesini ve gelişmesini sağlayan süreçler, yapılar ve uygulamalara dayanmaktadır (Vogus ve Sutcliffe, 2007). Bu sayede organizasyonlar, karşılaştıkları olumsuz durumlarla mücadele etme yollarını öğrenerek hayatta kalma ve sürdürülebilirlik gücünü kazanmaktadırlar.

Burnard ve Bhambra'nın (2011) nin altini çizdiği üzere "resilience” kavramı hem örgüt içinde hem de örgütler arası kırılmalarda bağlantıları koruyucu bir işleve sahiptir. Bunun nedeni yaşanabilecek krizlerin yalnızca örgüt içinde değil ayni zamanda paydaşlarla ilgili de olabilmesidir. Bir başka anlatımla, örgütü olumsuz etkileyebilecek dutumlar örgüt içi faaliyetler müşteri ilişkileri çalışan ilişkileri ve örgütün etkileşimde olduğu tüm diş çevre aktörleriyle bağlantılı olabilir. Bu bakış açısıyla "resilience" kavramının oldukça geniş kapsamlı etkileri olduğu düşünülebilir. Örgütsel "resilience" kavramını operasyonel (işevuruk) ve ilişkisel anlamda ele almak mümkündür (Yilmaz Borekci, Iseri Say, Kabasakal, ve Rofcanin, 2014).

Operasyonel (işevuruk) "resilience"; bir organizasyonun organizasyon içinde ve arasında operasyonel aksamalar olması durumunda görev tamamlama, iş performansı ve ürün sunumu dahil olmak üzere operasyonlarının hayatta kalması ve sürdürülebilirliği olarak tanımlanmaktadır (Yılmaz Börekçi vd., 2014). Örgütsel bağlamda "resilience" kavramı yalnızca operasyonlarla sınırlı kalmamaktadır. Ponomarov (2009) bu kavramı bir örgütler arası düzeyde incelemiş ancak esas olarak sürdürülebilirlik boyutuna dikkat etmeden ilişkisel esnekliğin hayatta kalma boyutuna odaklanmıştır. Kahn, Barton ve Fellows (2013) söz konusu kavramı, organizasyonlar arasındaki ilişkisel dinamikler açısından analiz etmiştir. Örgütsel dayanıklılık için ağların ve ilişkilerin önemini vurgulayan çalışmalar da bulunmaktadır (Seville vd., 2014; Brown, Seville ve Vargo, 2017). Bu bağlamda örgütsel bağlamda "resilience" (organziational resilience), operasyonel (işevuruk-operational) ve ilişkisel (relational) olmak üzere iki boyuttan oluşmaktadır. Bu boyutlar ise kendi içinde hayatta kalma (sağ kalım) ve sürdürülebilirlik alt boyutlarına sahiptir (Tablo 3). 
Ç.Ü. Sosyal Bilimler Enstitüsü Dergisi, Cilt 28, Sayı 2, 2019, Sayfa 198-213

Tablo 3. "Resilience" Kavramının Analitik Boyutları

\begin{tabular}{|c|c|}
\hline Boyutlar & Boyutların Kavramsallaştırılması \\
\hline \multirow[t]{2}{*}{$\begin{array}{l}\text { Operasyonel (İse vuruk) } \\
\text { “Resilience" (Operational resilience) } \\
\text { (Allen, 2011; Ponomarov, 2009; } \\
\text { Yllmaz Börekçi v.d., 2015) }\end{array}$} & $\begin{array}{l}\text { 1. Operasyonların (faaliyetlerin) hayatta kalması } \\
\text { (să̆ kalım-survival) } \\
\text { Kritik örgütsel faaliyetlerin ve süreçlerin sürekliliği } \\
\text { ve insan, makine, bilgi, teknoloji ve fabrika gibi } \\
\text { gerekli varlıkların devamlılığ }\end{array}$ \\
\hline & $\begin{array}{l}\text { 2.Operasyonların (faaliyetlerin) sürdürü̈lebilirliği } \\
\text { (sustainability) } \\
\text { Örgütteki ve örgütler arası faaliyet ve süreçlerin yanı } \\
\text { sira gereken varlıkların da uyarlanması ve } \\
\text { dönüştürülmesi }\end{array}$ \\
\hline \multirow{2}{*}{$\begin{array}{l}\text { Ilisskisel "Resilience” (Relational } \\
\text { resilience) } \\
\text { (Ponomarov, 2009; Kahn vd.,2013; } \\
\text { Yllmaz Börekçi vd., 2015) }\end{array}$} & $\begin{array}{l}\text { 1.İlişkilerin hayatta kalması (să̆ kalım-survival) } \\
\text { Karşılıklı güven davranışları, ilişkilerde uzun } \\
\text { dönemli yönelim ve bağlllık, ilişkilerin korunması }\end{array}$ \\
\hline & $\begin{array}{l}\text { 2. İlişkilerin sürdürülebilirliği (sustainability) } \\
\text { Yeni taraflarla ilişkiler kurabilme, yeni ilişkisel } \\
\text { dinamikler edinebilme, yeni ilişki birleşimleri } \\
\text { oluşturabilme, eski ilişkileri gerektiğinde bozabilme }\end{array}$ \\
\hline \multirow[t]{2}{*}{$\begin{array}{l}\text { Örgüt Bağlamında “Resilience” } \\
\text { (Organizational resilience) } \\
\text { (Glassop, 2007; Yllmaz Börekçi vd., } \\
\text { 2015; Sutcliff \& Vogus, 2003) }\end{array}$} & $\begin{array}{l}\text { 1.Örgü̈tün hayatta kalması (sağ kalım-survival) } \\
\text { Orgütlerin hayatta kalabilmesi için gerekli } \\
\text { kaynakları ve yetenekleri, karşıllklılık deneyimlerini } \\
\text { ve etkinliği korumak }\end{array}$ \\
\hline & $\begin{array}{l}\text { 2.Örgü̈tün sürdürüllebilirliği (sustainability) } \\
\text { Orgütsel kaynaklar ve yeterlilikler yaratan } \\
\text { dinamikler ve süreçler, deneyimlerin } \\
\text { birleşimilyeniden birleştirilmesi ve etkinliği arttırmak }\end{array}$ \\
\hline
\end{tabular}

Kaynak: Börekçi, D. Y., Rofcanin, Y., Heras, M. L., ve Berber, A. (2018). "Deconstructing organizational resilience: A multiple-case study”. Journal of Management \& Organization, 1-20.

\section{Çalışanlar Bağlamında "Resilience" Kavramı (Employee Resilience)}

Ôrgütsel bağlamda "resilience" kavramı ele alındığında, birey, grup ve örgüt düzeyi olmak üzere iç ana boyutun varlığı gözlenmektedir. Birey boyutu, çalışanların "resilience" kapasitesi olarak da ifade edilebilecek olan çalışan "resilience"1 (employee resilience) olarak yazında kullanılmaktadır. Çalışan "resilience"1 psikoloji ve örgütsel davranış alanında özellikle 2010 sonrası sıklıkla incelenmeye başlanan bir olgudur (Cooke,Cooper, Bartram, Wang, ve Mei, 2016; Tonkin, Malinen, Näswall, ve Kuntz, 2018).

Avey, Luthans ve Jensen'e (2008) göre, "resilience” çalışanların çalkantılı ve stresli işyeri durumları karşısında kullanabileceği içsel bir kaynaktır. Youssef ve Luthans (2007), bir kaynak olarak "resilience", geliştirildiğinde ve etkili bir biçimde yönetildiğinde bireysel ve örgütsel çıktıları olumlu etkileyebilme özelliğine sahip olduğunu öne sürmüşlerdir. Çalışan "resilience"ını etkili bir şekilde irdeleyebilmek için, psikolojik "resilience" kavramından ayrıştırılması önem taşımaktadır. Bunun nedeni, psikolojik "resilience" kavramının, bireylerin günlük yaşamda karşılaşabilecekleri zorluklar ve tehditler karşısında problem çözme ve hayatlarına devam edebilme becerileri ile ilgiliyken, çalışan "resilience"1nın örgüt tarafından desteklenen, başa 
çıkma, uyum sağlama ve dönüşme yeteneklerini geliştirecek kaynakları ifade etmesidir (Gerçek ve Yılmaz Börekçi, 2017; Tonkin vd., 2018). Bu bakış açısıyla, psikoloji alanında bireyler için kullanılan "resilience" kavramı ile örgüt alanında kullanılan "resilience" kavramı arasında belirgin farklılıklar olduğunu söylemek mümkündür.

"Resilience" kapasitesine sahip çalışanlar, zorluklar karşısında olumlu ve yetkin bir şekilde karşıllı verebilir ve sadece hayatta kalmak yerine gelişerek geri dönüp, belirsizlikten daha çok şey öğrenebilirler (Luthans, Avey, Avolio, Norman ve Combs, 2006). Çalışan "resilience"1, "zorlu koşullarla karşılaşıldığında, örgütte sürekli olarak uyum sağlamak ve gelişmek üzere kaynakları kullanmak için örgüt tarafından mümkün kııınan ve desteklenen çalışan kapasitesi” olarak tanımlanmıștır Kuntz, Naswall ve Malinen (2016). Kuntz vd.'nin (2016) kavramsallaştırmasına göre çalışan "resilience"1 üç temel varsayım üzerine kuruludur. Bu varsayımlar, bireysel "resilience"1 kapsamakla birlikte işlevsel olarak farklı olması; öğrenme, uyum sağlayabilme ve ağ olușturabilme gibi unsurlara dayanan davranış temelli bir kavram olması ve uygun örgütsel sistemlerin varlığında geliştirilebilir ve sürdürülebilir olmasıdır. Kuntz vd.'nin (2016) yaklaşımı, Luthans'ın (2002) dayanıklılık tanımını içermekle birlikte, daha önceki kuramlarda önerildiği gibi kararlı bir kişilik özelliği yerine "geliştirilebilir bir kapasite" olarak (bkz. Wagnild \& Young, 1993) tanımlanmıştır. Bu kapasitenin geliştirilmesi, çalışanların gelecekte daha esnek ve uyarlanabilir olmaları için değişim ve sıkıntı ile geçmiş deneyimlerden faydalanabilecekleri anlamına gelmektedir (Avey, Luthans ve Jensen, 2009; Tugade ve Fredrickson, 2004).

Bir örgütün "resilience" kapasitesi, sahip olunan örgütsel yetenekler, rutinler, uygulamalar ve süreçler olarak kabul edilmektedir (Lengnick-Hall ve Beck, 2005;2009). Kuntz vd.'nin (2013) varsayımlarında sözünü ettiği örgütsel destek, birey düzeyinde "resilience" kapasitesini geliştirmeyi amaçlayan bir takım politika, prosedür ve uygulamalardır. Lengnick-Hall vd.'ye göre (2011) örgütsel “resilience” kapasitesi, insan kaynakları yönetimi uygulamaları aracılığıyla geliştirilmiş bireysel bilgi, beceri, yetenek ve diğer özelliklerden beslenmektedir. Dolayısıyla, örgütsel "resilience" kapasitesinin ilk basamağının, çalışan "resilience" kapasitesini oluşturmak olduğu yorumu yapılabilir. Başka bir anlatımla, örgütlerin beklenmedik olaylar karşısında nasıl eyleme geçeceği, hayatta kalabilmeleri ve değişimlere ayak uydurabilmelerinin temelinde çalışanların bilişsel, davranışsal ve bağlamsal yeteneklerine bağlı olduğu söylenebilir. Çalışanların, örgütsel bağlamda operasyonel (işevuruk) ve ilişkisel düzeylerde benimseyeceği tutum ve davranışlar birikimli olarak grup ve örgüt düzeyindeki çıktılara yansıması öngörülmektedir. Tüm bu bilgiler ışığında özellikle son dönem çalışmalarda (örn. Britt vd., 2016; Nguyen vd., 2016; Shoss, Jiang ve Probst, 2016) çalsşanlar bağlamında "resilience" kavramının psikolojik bağlamdaki "resilience" kavramından ayrıştıııldığının görülmesi, Türkçe çalışmalarda da bu ayrımın kaçınılmaz hale geldiğine işaret etmektedir.

\section{Resilience Kavramının Türkçe Çalış̧malarda Tercih Edilen Karşılıkları ve Yeni Öneriler \\ "Resilience" kavramının sosyal bilimler kapsamında ulusal makale ve lisansüstü tezlerde eğitim, felsefe, işletme, psikoloji ve siyasal bilgiler alanlarında sıklıkla kullanılan bir kavram olduğunu söylemek mümkündür. Yılmaz Börekçi ve Gerçek'in}


(2017) çalışmasında, "resilience" kavramının sosyal bilimlerde çeşitli çalıșmalarda kullanılan Türkçe karşılıkları incelenmiştir. Bu çalışmada görüldüğü üzere, YÖK veri tabanında "resilience" kavramını içeren tezlerde ve ULAKBİM ulusal veri tabanında Türkçe karşılık olarak, dayanıklılık, dirençlilik, direniş, esneklik, kendini toparlama, sağlamlık ve yılmazlık kelimelerinin kullanıldığı görülmüştür (örn. Gizir, 2016; Öz ve Bahadır Yılmaz, 2009; Yıldırım, 2016; İşcan ve Malkoç, 2017). Bu çalışmada, YÖK Veri Tabanında "resilience" kavramını içeren lisansüstü çalışmalarda "resilience" kelimesinin Türkçe karşılığının alanlara göre dağılımı incelendiğinde en fazla lisansüstü tezin psikoloji alanında yapıldı ̆̆ı belirlenmiştir. Bütün alanlarda en çok tercih edilen Türkçe karşılığın ise “dayanıklılık” olduğu belirlenmiştir. Bu sonuçlara dayanarak, yapılan çalışmalardaki Türkçe karşılık tercihinin belirleyicisinin araştırmanın alanı ve amacı olduğu söylenebilmektedir.

Türkiye'de yönetim ve organizasyon alanında düzenlenen bir kongrede "resilience" kavramının işletme bağlamında kullanımında kelimenin okunuşu olan "rezilyans" kelimesi kullanılmıştır (Kırbaşlar ve Yılmaz Börekçi, 2014). Yazarların diğer bir çalışması ise "resilience" kelimesi yerine "Yine/yenilenme kapasitesi" ifadesi kullanılarak yayınlanmıştır (Gerçek ve Yılmaz Börekçi, 2017).

Daha önce bahsedildiği üzere, "resilience" kavramı farklı disiplinlerde farklı anlamlarda kullanılmaktadır. Bununla birlikte, başta işletme alanı olmak üzere örgüt bağlamında yapılan çalışmalarda da özellikle psikolojik açıdan bireysel düzeyde bir özellik olarak tanımlanan "resilience" kavramı için kullanılan dayanıklılık kelimesinin de kullanıldığı görülmüştür. Bu örgüt bağlamında kullanımı, öğrgütsel öğrenme, değişim-dönüşüm, sağ kalım-sürdürülebilirlik gibi "resilience" kapasitesinin temel unsurlarına çağrışım yapmakta yetersiz kalmaktadır. Bu bağlamda yeni bir kelime veya kelime grubunun önerilmesi uygun bulunmuştur.

"Resilience" (resilient) kavramını anlamsal olarak karşılamak üzere aşağıda yine/ yenilenme (yine/ yenilenen) ve sürdürerek aşma (sürdürerek aşan) Türkçe karşılık önerileri sunulmuştur. Bu öneriler yapılırken "resilience" kavramının güncel geniş kapsamının yani sağ kalım ve sürdürülebilirlik alt boyutlarının her ikisinin birden içerilmesine ve örgütsel bağlamda kullanımına dikkat edilmiştir. "Resilience" kavramı çok boyutlu bir kavram olduğu için, daha önceki çalışmalarda da görüldüğü üzere (bkz. "kendini toparlama") tek bir kelime ile dilimizde ifade edilmesinin güç olacağ düşünülerek bazı sözcük grupları önerilmiştir.

Yine/ Yenilenme (Yine/yenilenme veya Yine Yenilenme)

"Resilience" kavramı; hem yinelenme (eski formuna dönebilme, tekrar etme) hem de yenilenme (değişim, dönüşüm) yeteneği, kapasitesi ve süreci olduğu için her ikisini birlikte karşılayan bir kavram arayışında bu karşılık bulunmuştur. "Yine" kelimesi, Arapça “mükerrer”, Türkçe ise ilk olarak Orhun Yazıtları'nda rastlanan bir kelime olarak tekrarlamak, dönmek, geri getirmek anlamlarını taşımaktadır (Etimoloji Türkçe). "Yinelenme" kelimesi, Arapça "takarrür", tekrarlanmak, bir kez daha yapılmak anlamlarını taşımaktadır. "Yeni" kelimesi, bir sıfat olarak kullanılmamış, en son edinilen, o güne kadar söylenmemiş, görülmemiş, eskisinin yerine gelen anlamlarında kullanılmaktadır (Türk Dil Kurumu). "Yenilenmek" kelimesi, bir nesnenin yerine yenisinin konulması ve canlanmak anlamlarını taşımaktadır (Türk Dil Kurumu). Yine/Yenilenme ifadesinin "resilience" kavramının eski haline dönme (yine) ve değişimlere uyum sağlayarak eskisinden daha iyi bir hale gelme (yenilenme) 
özelliklerini açıklamakta yeterli olduğu söylenebilir. Yazarların önceki çalışmalarında da (Gerçek ve Yılmaz Börekçi, 2017; Gerçek ve Yılmaz Börekçi (yayın aşamasında)) örgüt bağlamında "resilience" kavramının karşılığı olarak "yine/yenilenme" ifadesi kullanılmış ve kabul görmüştür.

"Yine-yeni-yeniden" kelime grubu dilimizde şarkı sözlerinde de yer almış (Tunç ve Gürel, 1992), günlük dilde de olumsuzluklara rağmen devam etme karalılığını anlatmak üzere kullanımda olan bir ifadedir. Yine/ yenilenme ifadesinin tek kelime olmaması ve taksim işaretiyle kullanımı dezavantaj olarak görülebilir. Ayrıca yinelenme ve yenilenme iç içe geçmeden ziyade kesintili süreçler çağrışımı yapabilir. $\mathrm{Bu}$ bakımdan, taksim işareti olmadan "yine yenilenme" kullanımı da düşünülebilir.

Sürdürerek Aşma

Sürdürerek aşma ifadesi makale yazarlarından birinin sinema ile ilgili bir okuması (Kayalı, 1994) sırasında dikkatini çekmiştir. Buradaki sürdürme (orijinal form) ve aşmanın (değişme, dönüşme) iç içe oluşu ve tekil bir ifade gibi algılanması "resilience" kavramının karşılığı olarak kullanılabilme gücünü göstermektedir. Sürdürme ifadesinin arada yaşanabilecek kopuklukları ve tökezlemeleri gizlemesi olumsuz olarak değerlendirilebilir.

\section{Sonuç ve Tartışma}

Bu çalışmanın amacı, farklı disiplinlerde kullanılan "resilience" kavramının özellikle işletme alanında örgüt bağlamında yapılacak çalışmalar için kullanılmak üzere bir Türkçe karşılık önerisi sunmaktadır. Bu amaç doğrultusunda, "resilience” kavramının tanımı ve kullanım alanları hakkında gerekli bilgiler sunulduktan sonra örgüt ve çalışan bağlamında ne anlama geldiği irdelenmiștir. Yapılan tanımlardan hareketle, "resilience" kavramının farklı bilim dallarında benzer anlamları taşıdığ 1 ancak, birebir aynı anlama gelmediği yorumu yapılabilir. Dolayısıyla bu çalışmada, "resilience" kavramını, işletme, endüstri mühendisliği, örgüt araştırmaları gibi alanlarda diğer alanlardan ayrıştırabilecek örgüt ve çalışan bağlamında Türkçe karşılıklar önerilmesi uygun görülmüştür.

"Resilience" kavramı hızla gelişen teknolojiye bağlı olarak değişken çevre koşulları sonucu örgütlerin krizlere daha açık hale gelmesiyle örgüt çalışmalarında sıklıkla tercih edilen bir unsur olarak ele alınmaktadır. "Resilience" kavramının örgüt ve çalışan bağlamında önem taşımasının başlıca nedeni, örgütlerin beklenmedik tehditler karşısında nasıl ayakta kalabileceklerine yönelik stratejiler geliştirmeye başlamasıdır. Bir başka deyişle, örgütler zaman içinde nasıl krizlere karşı ayakta durabileceklerinin cevabını "resilience" kapasitesi geliştirmekte bulmuşlardır. Bir örgütün krizlere karşı ayakta durabilme ve gerektiğinde uyum sağlayabilme gücü olarak tanımlanan örgütsel "resilience", birey düzeyinde çalışanlarla başlayan bir süreç olmasının yanı sıra bilişsel, davranışsal ve bağlamsal bir bileşimdir (Lengnick-Hall vd., 2011). "Resilience" kavramı, yalnızca eski haline dönmeyi değil, örgütsel öğrenme yöntemleriyle hatalardan ders çıkarmayı ve yeni özellikler kazanarak yeni bir şekle bürünebilme anlamını da içinde taşımaktadır. Bu bilgiler 1şığında, örgüt bağlamında kullanılan "resilience" kavramının diğer disiplinlerdeki kullanımlarından oldukça farklı olduğunu söylemek mümkündür. 
Türkiye kökenli çalışmalarda, "resilience” kavramının Türkçe karşılığı olarak oldukça farklı seçimler yapıldığı görülmüştür (Yılmaz Börekçi ve Gerçek, 2017). Bu seçimler genellikle kullanım alanına ve kullanım amacına göre değişmektedir. Özellikle işletme alanında olmak üzere, endüstri mühendisliği ve örgüt psikolojisi gibi alanlarda da psikoloji, eğitim ve tıp alanlarında kullanılan Türkçe karşılıkların tercih edilmesinin gerek örgüt bağlamındaki anlamı karşılamakta yetersiz olması gerekse anlam karmaşası yaratması bakımından olumsuz bir durum olduğu söylenebilir. Bu bakımdan, örgüt ve çalışan bağlamında yapılan çalışmalarda "resilience" kavramı üzerinde görüş birliği sağlanacak Türkçe bir karşılığın bulunmasının araştırmacılar, uygulamacılar ve öğrenciler için oldukça faydalı olacağı düşünülmüştür.

Bu çalışmada "resilience" kavramının örgüt ve çalışan bağlamında kullanımı için iki adet kelime grubu önerilmiştir. "Resilience" kavramının çok boyutlu anlam zenginliği karşısında tek bir kelimenin yeterli olmayacağ 1 görüşüyle kelime gruplarının tercih edilmesi uzmanların görüşüne sunulmuştur. İlk öneri "yine/yenilenme", "resilience" kavramının eski haline dönme ve yeni özellikler kazanarak dönüşme anlamlarını içeren sağ kalım ve sürdürülebilirlik boyutlarını çağrıştırmakta anlamlı bulunmuştur. $\mathrm{Bu}$ önerinin yine/ yenilenme ve yine yenilenme formları da ifade edilmiştir. İkinci öneri olan "sürdürerek aşma" ifadesi ise sağ kalım sağlanırken eskisinden daha iyi bir hale gelme anlamını taşımaktadır. İki önerinin de olumlu ve olumsuz yanları bulunmaktadır. "Resilience" kavramı için yazarlar daha önceki çalışmalarında "yine/yenilenme" ifadesini tercih etmişlerdir. Bu öneriler, dilbilimciler ve ilgili alanlardaki uzmanların görüşüne sunulmuştur. Getirilen önerilerin, örgüt ve çalışan bağlamında "resilience" konusunu inceleyen araştırmacıların ve öğrencilerin ilgili yayınlara ulaşmalarında ve onları anlamalarında faydalı olması beklenmektedir.

\section{Kaynaklar}

Akgün, A.E. ve Keskin, H. (2014). Organisational resilience capacity and firm product innovativeness and performance, International Journal of Production Research, 52(23),6918-6937.

Allen, J. (2011). Measures for managing operational resilience. EDPACS: The EDP Audit, Control, and Security Newsletter,44(6), 1-6.

Avey, J. B., Luthans, F., ve Jensen, S. M. (2009). Psychological capital: A positive resource for combating employee stress and turnover. Human resource management, 48(5), 677-693.

Avey, J. B., Luthans, F., ve Jensen, S. M. (2009). Psychological capital: A positive resource for combating employee stress and turnover. Human resource management, 48(5), 677-693.

Bhamra, R., Dani, S. ve Burnard, K. (2011). Resilience: the concept, a literature review and future directions, International Journal of Production Research, 49(18), 5375-5393.

Block, J. Ve Kremen, A. M. (1996). IQ and ego-resiliency: conceptual and empirical connections and separateness, Journal Of Personality And Social Psychology, $70(2), 349$.

Britt, T. W., Shen, W., Sinclair, R. R., Grossman, M. R., ve Klieger, D. M. (2016). How much do we really know about employee resilience?. Industrial and 
Organizational Psychology, 9(2), 378-404.

Brown, C., Seville, E., ve Vargo, J. (2017). Measuring the organizational resilience of critical infrastructure providers: A New Zealand case study. International Journal of Critical Infrastructure Protection, 18, 37-49.

Cambridge English Dictionary, https://dictionary.cambridge.org/dictionary/english/resilience, Erişim Tarihi: 05.07.2019

Carmeli, A., Friedman, Y. Ve Tishler, A. (2013). Cultivating a resilient top management team: The importance of relational connections and strategic decision comprehensiveness, Safety science, 51(1), 148-159.

Chang-Richards, Y. S., Wilkinson, S., Seville, E., ve Brunsdon, D. (2017). An organizational capability framework for earthquake recovery. Earthquake Spectra, 33(4), 1257-1278.

Cooke, F. L., Cooper, B., Bartram, T., Wang, J., ve Mei, H. (2016). Mapping the relationships between high-performance work systems, employee resilience and engagement: A study of the banking industry in China. The International Journal of Human Resource Management, 1-22.

Coutu, D. L. (2002). How resilience Works, Harvard Business Review, 80(5), 46-56.

Etimoloji Türkçe, https://www.etimolojiturkce.com, Erişim Tarihi: 05.07.2019

Gerçek, M. ve Yılmaz Börekçi D., (Yayın aşamasında). Bireysel Yine/Yenilenmeyi (Rezilyansı) Destekleyici İnsan Kaynakları Yönetimi Uygulamalarına İlişkin Bir Ölçek Geliştirme Çalışması. Sosyal ve Beşeri Bilimler Araştırmaları Dergisi

Gerçek, M., ve Yılmaz Börekçi, D. (2017). Birey Düzeyinde İlişkisel ve Operasyonel Rezilyans (Yine/Yenilenme) Kapasitesi: Bir Ölçek Geliştirme Çalışması. İşletme Araştırmaları Dergisi ISARDER, 9(3), 149-176.

Gizir, C. A. (2016). Psikolojik Sağlamlık, risk faktörleri ve koruyucu faktörler üzerine bir derleme çalışması. Türk Psikolojik Danışma ve Rehberlik Dergisi, 3(28), 113 128.

Glassop, L. (2007). The three R's of resilience: Redundancy, requisite variety and resources. In R. Kay \& K. A. Richardson (Eds.), Building and Sustaining Resilience in Complex Organisations (pp. 19-34). San Antonio, TX: ISCE.

Hamel, G., ve Valikangas, L. (2003). The quest for resilience. Harvard Business Review, 81(9), 52-63.

Holling, C. S. (1973). Resilience and stability of ecological systems, Annual Review Of Ecology And Systematics, 1-23.

Holling, C. S. (2001). Understanding the complexity of economic, ecological and social system". Ecosystems, 4, 390-405.

Horne, J.F. ve Orr, J.E. (1998). Assessing behaviors that create resilient organizations, Employment Relations Today, 24, 29-40.

İşcan, G. Ç., ve Malkoç, A. (2017). Özel Gereksinimli Çocuğa Sahip Ailelerin Umut Düzeylerinin Başa Çıkma Yeterliği ve Yılmazlık Açısından İncelenmesi. Trakya Üniversitesi Eğitim Fakültesi Dergisi, 7(1), 120-127.

Kahn, W., Barton, M. ve Fellows, S. (2013). Organizational crises and the disturbance of relational systems. Academy of Management Review, AMR-2011.

Kayalı, K. (1994). Yönetmenler Çerçevesinde Türk Sineması. Ankara: Ayyıldız Yayınlar1. 
Kırbaşlar, M. ve Yılmaz Börekçi, D., İnsan Kaynakları Yönetimi Aracılığıyla İlişkisel ve Operasyonel Rezilyans Kapasitesi Oluşurma, 23. Ulusal Yönetim ve Organizasyon Kongres, Muğla, Türkiye, 14-16 Mayıs, Cilt 1, 436-441.

Klein, R. J., Nicholls, R. J., ve Thomalla, F. (2003). Resilience to natural hazards: How useful is this concept?, Global Environmental Change Part B: Environmental Hazards, 5(1), 35-45.

Kuntz, J. R., Näswall, K., ve Malinen, S. (2016). Resilient employees in resilient organizations: Flourishing beyond adversity. Industrial and Organizational Psychology, 9(2), 456-462.

Latin- Dictionary, https://latin-dictionary.net/definition/33432/resilio-resilire-resilui, Erişim Tarihi: 05.07.2019

Lee, A. V., Vargo, J., ve Seville, E. (2013). Developing a tool to measure and compare organizations' resilience. Natural Hazards Review, 14(1), 29-41.

Lengnick-Hall, C. A. ve Beck, T. E. (2005). Adaptive fit versus robust transformation: How organizations respond to environmental change, Journal of Management, 31(5), 738-757.

Lengnick-Hall, C. A., Beck, T. E. ve Lengnick-Hall, M. L. (2011). Developing a capacity for organizational resilience through strategic human resource management, Human Resource Management Review, 21(3), 243-255.

Lengnick-Hall, C. A., ve Beck, T. E. (2009). Resilience capacity and strategic agility: Prerequisites for thriving in a dynamic environment. In C. Nemeth, E. Hollnagel, \& S. Dekker (Eds.), Resilience engineering perspectives (pp. 39-69). Aldershot: Ashgate Publishing.

Luthans, F. (2002). The need for and meaning of positive organizational behavior, Journal Of Organizational Behavior, 23(6), 695-706.

Luthans, F., Avey, J. B., Avolio, B. J., Norman, S. M., ve Combs, G. M. (2006). Psychological capital development: toward a micro-intervention. Journal of Organizational Behavior: The International Journal of Industrial, Occupational and Organizational Psychology and Behavior, 27(3), 387-393.

Luthans, F., Vogelgesang, G. R. ve Lester, P. B. (2006). Developing the psychological capital of resiliency, Human Resource Development Review, 5(1), 25-44.

McDonald, N. (2006). Organisational resilience and industrial risk, Resilience engineering. Concepts and precepts. Aldershot: Ashgate.

Merriam-Webster Dictionary, https://www.merriamwebster.com/dictionary/resilience\#note-1, Erişim Tarihi: 05.07.2019

Nguyen, Q., Kuntz, J. R., Näswall, K., ve Malinen, S. (2016). Employee resilience and leadership styles: The moderating role of proactive personality and optimism. New Zealand Journal of Psychology (Online), 45(2), 13.

Nilakant, V., Walker, B., van Heugten, K., Baird, R., ve de Vries, H. (2013). Research note: Conceptualising adaptive resilience using grounded theory. New Zealand Journal of Employment Relations, 39(1), 6-18.

Oxford English Dictionary, https://www.lexico.com/en/definition/resilience, Erişim Tarihi: 05.07.2019

Öz, P. D. F., ve Yılmaz, U.H.E B.(2009). Ruh sağlığının korunmasında önemli bir kavram: Psikolojik sağlamlık. Hacettepe Üniversitesi Hemşirelik Fakültesi Dergisi, 16(3), 82-89. 
Ç.Ü. Sosyal Bilimler Enstitüsü Dergisi, Cilt 28, Sayı 2, 2019, Sayfa 198-213

Ponomarov, S. Y. (2009). Understanding operational and relational resilience in buyersupplier dyads. Society for Marketing Advances (SMA) Conference Proceedings, New Orleans, LA, November 2009.

Ponomarov, S. Y., ve Holcomb, M. C. (2009). Understanding the concept of supply chain resilience, The International Journal of Logistics Management, 20(1), 124143.

Seville, E., Stevenson, J. R., Brown, C. O., Giovinazzi, S., ve Vargo, J. (2014). Disruption and resilience: How organisations coped with the Canterbury earthquakes, GNS Science.

Shoss, M. K., Jiang, L., ve Probst, T. M. (2018). Bending without breaking: A twostudy examination of employee resilience in the face of job insecurity. Journal of occupational health psychology, 23(1), 1-15.

Sutcliffe, K.M. ve Vogus, T.J. (2003). Organizing for Resilience, In Cameron, K., Dutton, J.E., and Quinn, R.E. (Eds.), Positive Organizational Scholarship. San Francisco: Berrett-Koehler. Chapter 7, 94-110.

Timmerman, P. (1981). Vulnerability, Resilience and the collapse of Society, A Review of Models and Possible Climatic Applications, Toronto, Canada: Institute for Environmental Studies, University of Toronto.

Tonkin, K., Malinen, S., Näswall, K., ve Kuntz, J. C. (2018). Building employee resilience through wellbeing in organizations. Human Resource Development Quarterly, 29(2), 107-124.

Tugade, M. M., ve Fredrickson, B. L. (2004). Resilient individuals use positive emotions to bounce back from negative emotional experiences. Journal of personality and social psychology, 86(2), 320.

Tunç, O. ve Gürel, A. (1992). "Yine Yeni Yeniden Sev", http://www.turkcewiki.org/wiki/Aysel_G\%C3\%BCrel_taraf\%C4\%B1ndan_yaz $\% \mathrm{C} 4 \% \mathrm{~B} 11 \mathrm{~m} \% \mathrm{C} 4 \% \mathrm{~B} 1 \% \mathrm{C} 5 \% 9 \mathrm{~F}+\% \mathrm{C} 5 \% 9$ Fark\%C4\%B1lar_listesi, $\quad$ Erişim Tarihi: 05.07.2019

Türk Dil Kurumu, Türkçe Sözlük, http://sozluk.gov.tr/, Erişim Tarihi: 05.07.2019

Vogus, T.J. ve Sutcliffe, K.M. (2007). Organizational resilience: towards a theory and research agenda. In Systems, Man and Cybernetics, 2007. ISIC. IEEE International Conference on Oct 7, 3418-3422.

Wagnild, G. ve Young, H. (1993). Development and psychometric, Journal Of Nursing Measurement, 1(2), 165-178.

Waite, P. J. ve Richardson, G. E. (2004). Determining the efficacy of resiliency training in the work site, Journal of Allied Health, 33(3), 178-183.

Yıldırım, G. (2016). Okul Öncesi Öğretmenlerinin Meslekten Tükenmişlik Ve Psikolojik Yılmazlık Düzeyi İlişkisi. Electronic Turkish Studies, 11(14), 811826.

Yılmaz Börekçi, D. ve Gerçek, M. (2018). "Resilience" Kavramının Sosyal Bilimlerde Türkçe Kullanımları Bağlamında Değerlendirilmesi. Pamukkale Üniversitesi Sosyal Bilimler Enstitüsü Dergisi, (30), 41-51.

Yilmaz Borekci, D., Iseri Say, A., Kabasakal, H., ve Rofcanin, Y. (2014). The quality of relationships with alternative suppliers: The role of supplier resilience and perceived benefits in supply networks. Journal of Management \& Organization, 20,808-831. 
Ç.Ü. Sosyal Bilimler Enstitüsü Dergisi, Cilt 28, Sayı 2, 2019, Sayfa 198-213

Yilmaz Borekci, D., Rofcanin, Y., ve Gurbuz, H. (2015). Organizational resilience and relational dynamics in triadic networks: A multiple case analysis. International Journal of Production Research, 53, 6839-6867.

Yilmaz Borekci, D., Rofcanin, Y., Heras, M. L., ve Berber, A. (2018). Deconstructing organizational resilience: A multiple-case study. Journal of Management \& Organization, 1-20.

Youssef, C. M., ve Luthans, F. (2007). Positive organizational behavior in the workplace: The impact of hope, optimism, and resilience. Journal of Management, 33(5), 774-800. 